\title{
0912 IT WAS A FREAK ACCIDENT: ANALYSIS OF THE PRESENTATION OF INJURIES AND DEATHS IN THE US PRESS
}

K C Smith*, A Gielen, S Baker, D Girasek, A Samuels Correspondence: Johns Hopkins Bloomberg School of Public Health, 624 N. Broadway, Room 726, Baltimore, MD 21030, USA

10.1136/ip.2010.029215.912

A key tenet of injury control is that to the extent that injury is seen as unavoidable, so the power of known, effective prevention strategies is limited. The term accident has long been construed as part of the problem as it is highly associated with public conceptualisation of injury, and yet also inherently negates notions of responsibility and predictability. Social constructionist theories provide tools to understand how key ideas and concepts are created, sustained and ultimately challenged and changed. Framing theory presents the news media as a powerful mechanism through which the public is provided with the critical concepts to understand the nature of key (newsworthy) events that occur within their social world, but outside of their immediate experience. We present data from an analysis of how and when the term Freak Accident is applied within the U.S. news media. We argue that while this term has media utility, it is inherently problematic for injury prevention. Data result from a search of stories produced by the Associated Press within the prior 5 years in which the term Freak accident appeared anywhere within the text. Stories that did not pertain to human injury were excluded, yielding a dataset of 262 relevant stories for analysis. Using a qualitative textual analytic methodology, we consider the nature of events being defined as freak accidents, who defines the events in this way, and the severity of the injuries sustained. We apply these findings to intervention opportunities for media advocacy and media education programs. 